\title{
Detection of anti-ganglioside antibodies in Guillain-Barré syndrome
}

\author{
Wenli Zhu, Ke Li, Tingting Cui, Yaping Yan \\ Key Laboratory of the Ministry of Education for Medicinal Resources and Natural Pharmaceutical Chemistry, National Engineering Laboratory for \\ Resource Development of Endangered Crude Drugs in Northwest of China, College of Life Sciences, Shaanxi Normal University, Xi'an, China \\ Contributions: (I) Conception and design: All authors; (II) Administrative support: None; (III) Provision of study materials or patients: All authors; \\ (IV) Collection and assembly of data: All authors; (V) Data analysis and interpretation: All authors; (VI) Manuscript writing: All authors; (VII) Final \\ approval of manuscript: All authors. \\ Correspondence to: Yaping Yan. College of Life Sciences, Shaanxi Normal University, Xi'an 710119, China. Email: yaping.yan@snnu.edu.cn.
}

\begin{abstract}
Gangliosides are a class of glycosphingolipid molecules that are highly enriched in cellular membranes of the nervous system. The gangliosides associated with autoimmune diseases of the nervous system are mainly GM1, GD1a, GalNAc-GD1a, GM1b, GD3, CD1b, GT1a, and GQ1b. Multiple antibodies recognizing gangliosides are associated with some acute or chronic peripheral neuropathies, especially Guillain-Barré syndrome (GBS) and its clinical variants. Antibodies binding to gangliosides can activate complement system and recruit macrophages on the axolemma at the nodes of Ranvier of motor fibers, which are found in the course of GBS, causing axonal degeneration and reversible conduction block or conduction failure. Testing of anti-gangliosides autoantibodies is helpful for diagnosis of autoimmune peripheral neuropathies or support the diagnosis of the subtypes. These anti-gangliosides antibodies are usually detected by several qualitative or quantitative methods, particularly enzyme-linked immunosorbent assay (ELISA) and immunodot assays, which have been commercialized or established in-house worldwide. Herein, we introduce the methods and clinical applications of these assays in the diagnosis of autoimmune peripheral neuropathies. Anti-gangliosides antibodies are diagnostic markers of GBS subtypes. We use GBS as an example to explain the role of anti-gangliosides antibodies in the pathogenesis and diagnostic classification of neuropathies.
\end{abstract}

Keywords: Anti-gangliosides antibodies; Guillain-Barré syndrome (GBS); detection methods; clinical applications

Submitted Mar 08, 2020. Accepted for publication Mar 05, 2021. Published online Apr 21, 2021.

doi: $10.21037 / \mathrm{atm}-20-2285$

View this article at: http://dx.doi.org/10.21037/atm-20-2285

\section{Introduction}

Gangliosides, mainly located in the outer layer of the bilayer structure of the neuronal cell membrane, play important roles in cellular growth and differentiation, signal transduction, and immune reactions $(1,2)$. Primary gangliosides associated with nervous system autoimmune diseases are GM1, GD1a, GalNAc-GD1a, GM1b, GD3, CD1b, GT1a, and GQ1b (3-6). Anti-ganglioside antibodies binding to the corresponding gangliosides, activate the complement system and lead to neural damage, including axonal degeneration and loss of myelin (4). IgG and complement deposits on the axolemma at the nodes of Ranvier of motor fibers are found early in the course of the disease. Clinical manifestations are variable and electrophysiological features are axonal degeneration and block conduction $(4,7)$. The functions of gangliosides in auto-immune reactions may depend on their carbohydrate and ceramide structures (3): the hydrophobic ceramide tail of gangliosides is embedded in the lipid bi-layer of the plasma membrane, usually in the cholesterolenriched microdomains, while the extracellular hydrophilic 
Table 1 Target antigens of anti-ganglioside antibodies testing based on clinical features of GBS

\begin{tabular}{lll}
\hline Classification & Clinical features & Presence of anti-ganglioside antibodies \\
\hline MFS & Ophthalmoplegia, ataxia and flexia/hyporeflexia & Anti-GQ1b, anti-GT1a (14,15) \\
BBE & Hypersomnolence and ophthalmoplegia and ataxia without limb weakness & AntiGQ1b, antiGD1b (16) \\
AIDP & Paresthesia, limb weakness & Anti-GM1, anti-GD1a (17) \\
AMAN & Weakness without paresthesia & Anti-GD1a, anti-GM1 (18,19) \\
PCB & Bulbar, cervical and upper limbs & Anti-GT1a, anti-GQ1b (20) \\
AMSAN & Weakness accompanied by paresthesia & Anti-GM1, anti-GM1b, anti-GD1a (5,21) \\
\hline
\end{tabular}

AMAN, acute motor axonal neuropathy; GBS, Guillain-Barré syndrome; AIDP, acute inflammatory demyelinating polyradiculoneuropathy; MFS, Miller Fisher syndrome; PCB, pharyngeal-cervical-brachial variant; AMSAN, acute motor and sensory axonal neuropathy; BBE, Bickerstaff brainstem encephalitis.

Table 2 Target antigens of anti-glycolipid antibodies located in human peripheral nerves

\begin{tabular}{ll}
\hline Classification & Localization in PNS \\
\hline GQ1b & $\begin{array}{l}\text { The extramedullary part of the cranial nerve and } \\
\text { the presynaptic membrane of the neuromuscular } \\
\text { junction }(23,24)\end{array}$ \\
GD1b & Large neurons in DRG, paranodal myelin (25) \\
GM1 & $\begin{array}{l}\text { The axolemma at the nodes of Ranvier, the } \\
\text { myelin of motor nerves, and dorsal root ganglia }\end{array}$ \\
& $\begin{array}{l}\text { (26) } \\
\text { GD1a }\end{array}$ \\
GT1a & Glossopharyngeal and vagus nerves (28) \\
GalNAc-GD1a & $\begin{array}{l}\text { Axonal membrane of motor nerves at node and } \\
\text { paranode, axolemma of small fibers in sural } \\
\text { nerves (29) }\end{array}$ \\
\hline
\end{tabular}

PNS, peripheral nervous system; DRG, dorsal root ganglion.

oligosaccharide moiety is exposed to specific autoantibodies, and its conformations can be varied to enhance or reduce the autoantibody binding affinity, depending on the binding requirements for a particular antibody $(8,9)$.

Guillain-Barré syndrome (GBS) is a broad term used to describe a number of acute inflammatory immunemediated syndromes consisting of sensory dysfunction, autonomic dysfunction, progressive weakness and pain (10). By the clinical symptoms and nerve conduction test, GBS is classified into several subtypes: acute inflammatory demyelinating polyradiculoneuropathy (AIDP), acute motor and sensory axonal neuropathy (AMSAN); pharyngealcervical-brachial variant (PCB); Miller Fisher syndrome (MFS) and Bickerstaff brainstem encephalitis (BBE); and pure motor GBS, which is subdivided into acute motor axonal neuropathy (AMAN) and acute motor demyelinating neuropathy $(11,12)$. As a treatable rare disease, timely diagnosis and subtype-classification play crucial roles in GBS treatment (13). In this review, we discuss the different types of GBS and clinical features associated with antiganglioside antibodies (Table 1).

\section{Correlation between GBS and anti-ganglioside antibodies}

Premorbid infection with micro-organisms, such as Campylobacter jejuni (C. jejuni), is recognized as a main triggering event for GBS. Lipooligosaccharides (LOS) on the surface of both infectious micro-organisms and ganglioside lipopolysaccharides (LPS) induces cross-reactive humoral and cellular immune responses to nerve structures. Patients with GBS carry anti-ganglioside antibodies, resulting in autoimmune targeting of the peripheral nervous system (PNS), and leading to neural damage or functional impairment (22). Targeting gangliosides of different autoantibodies locate in different parts of the PNS (Table 2). Heterogeneity of ganglioside expression in the PNS may cause differential clinical manifestations of GBS and the GBS variants (30).

Gangliosides are required for axonal regeneration and stabilization of cytoskeletal structures. Therefore, ganglioside antibodies may inhibit nerve reparative processes (31). The antibodies binding to the exposed neuron membrane, such as Ranvier's neuromuscular junctions and lymph nodes, causing disordered ion channel regulation and axonal conduction disorders $(9,31)$, and results in axonal degeneration (32). Several studies reported the role of complement activation in mediating axonal 
injury in inflammatory neuropathy. Anti-GM1 and GD1a antibodies binding to gangliosides activate the complement system, and lead to the dysfunction of the PNS and conduction block $(33,34)$.

Gangliosides have long been used intravenously as a neurotrophic drug in China. However, safety concerns for GBS following intravenous ganglioside treatment were aroused in Europe several decades ago (35). Gangliosideassociated GBS was reported to manifest more functional deficits and poorer outcomes after standard treatment with gangliosides in China (36). High titers of anti-GM1 and GT1a antibodies were found in some of the patients who developed GBS following intravenous ganglioside treatment. GM1 is the major immunogen (37). However, the etiology of GBS is still unclear. One explanation is that the low purity of gangliosides may alter the individual's susceptibility by molecular mimicry, and trigger GBS (36).

GM1 locates on the axolemma at the nodes of Ranvier, the myelin of motor nerves, and dorsal root ganglia $(26,38)$. Anti-GM1 antibody is associated with a pure motor variant of GBS without sensory loss $(14,39)$. AMAN subtype of GBS is characterized by primary axonal degeneration, which is rare (about $5 \%$ of all GBS cases) in North America and Europe, but is the most prevalent form of GBS in China and Japan $(40,41)$. GD1a is mainly distributed in the Ranvier node of motor neurons, and the $\mathrm{IgG}$ form of anti-GD1a antibody is also closely associated with the AMAN (27). In Asia, including China, nearly half of the patients with GBS are eventually diagnosed with AMAN, of which approximately $60 \%$ of the patients are anti-GM1 and GD1a autoantibody positive $(17,42)$. Anti-GM2 antibodies are positive in some cytomegalovirus-infected individuals, but association with the incidence of GBS is still controversial (43). N-acetylgalactosaminyl GD1a (GalNAcGD1a) has been reported as the most potent target antigen in AMAN $(41,44,45)$. GalNAc-GD1a exists in the nodes of Ranvier in motor nerves and locates on the membrane of motor nerves at node and paranode, and the axolemma of small fibers in sural nerves (29). Anti-GalNAc-GD1a IgG antibody may cause conduction failure of motor nerves by binding the axolemma at nodes or nerve terminals, which is closely associated with AMAN and pure motor GBS (46). Anti-GM1b IgG antibodies are closely associated with pure motor GBS. Some anti-GM1b-antibody positive GBS patients also had anti-GM1 and anti-GalNAc-GD1a antibodies (47). AIDP patients rarely have anti-GD3 antibody (48). However, the precise localizations of GD1a, GM1b, and GD3 in motor nerves has not yet been confirmed.

In MFS, the antibodies of $C$. jejuni, produced during prior infection, can partially cross-recognize the ganglioside GQ1b and GM1 and contribute to MFS pathogenesis. The dense distribution of GQ1b exists in paranodal myelin of oculomotor, trochlear and abducens nerves, and some large neurons in the dorsal root ganglion could also be immunostained by monoclonal anti-GQ1b antibody (49). The distribution of GQ1b is critical for the symptomatology of MFS. Anti-GQ1b antibodies bind to GQ1b at these locations, causing nerve damage or conduction block (23). Anti-GQ1b antibody is closely associated with extraocular muscle paralysis, ataxia, and a possible cause of decreased levels of consciousness in BBE patients. After plasma exchange in patients with MFS, the levels of serum anti-GQ1b IgG antibody decreased, and extraocular muscle paralysis and ataxia symptoms were alleviated $(15,50)$. The cross-reactivity of anti-GQ1b antibody with GD1b is involved in the development of impaired deep sense in MFS (51).

Other anti-ganglioside antibodies, for example GT1a, are densely expressed in human glossopharyngeal and vagus nerves, and PCB patients often have antiGT1a IgG antibodies (28). AntiGQ1b antibodies were detected in $65 \%$ of ataxic GBS, and $18 \%$ of GBS with acute sensory ataxic neuropathy. AntiGD1b antibodies without GQ1b crossreactivity were found in $14 \%$ of ataxic GBS, and $35 \%$ of GBS with acute sensory ataxic neuropathy (52).

Anti-gangliosides antibodies are used as diagnostic markers of some subtypes and to support the diagnosis of other subtypes. For example, the existence of antiGQ1b antibodies in $83 \%$ of MFS patients and $68 \%$ of $\mathrm{BBE}$ patients demonstrated that these disorders belong to the same disease spectrum $(53,54)$. Some GBS patients with limb weakness and retained deep tendon reflexes are more likely to have anti-GM1 or anti-GM1a antibodies, neurophysiological features consistent with AMAN, compared with patients with decreased reflex. The presence of antiGT1a or antiGQ1b IgG antibodies further supports the clinical diagnosis of PCB weakness or one of its incomplete forms. The presence of antiGQ1b or antiGD1b antibodies can further confirm the clinical diagnosis of these MFS subtypes $(52,55)$. The detection rate of anti-GD1b antibody was $35 \%$ of the patients with acute sensory ataxic neuropathy (the detection rate was $14 \%$ in ataxia GBS) $(56,57)$. Although antiganglioside antibody testing can be informative for classifying GBS, the classification system does not stipulate the results of antiganglioside antibody testing. 


\section{Detection methods of anti-ganglioside antibodies}

A major obstacle in the detection of anti-ganglioside antibodies is that gangliosides are different from classic antigens. First, Low molecular weight may have steric hindrance to impede antibody binding (38). Second, gangliosides, unlike proteins, are difficult to be separated and displayed using well-developed methods that rely on molecular weight or charges, such as polyacrylamide gel electrophoresis, so anti-ganglioside antibodies are hard to be detected using western blot. Third, there is no reliable cell overexpression method for gangliosides, so the antiganglioside antibody cannot be detected by cell-based assay, which has been widely used in anti-membrane protein antibodies testing $(58,59)$. Fourth, similar skeletons of some gangliosides can cause cross-reaction (51). Antiganglioside antibodies are detected in serum using enzyme linked immune sorbent assay (ELISA), immunodot assays, thin-layer chromatography (TLC) overlay, agglutination tests, and flow cytometry $(56,57,60,61)$. Conventionally, in house or commercially available ELISAs and nitrocellulose/ polyvinylidene fluoride (PVDF) dot blots are used, in which purified gangliosides as the adhered antigens are probed with sera from patients with neuropathies. In this review, we mainly focus on current and emerging detection methods of anti-gangliosides antibodies.

\section{Enzyme-linked immunosorbent assays (ELISAs)}

ELISAs are immunoassays with the sensitivity of enzyme reactions that are based on the specific binding of antibodies to antigens to a solid phase-bound substance. These antigens can be glycolipids, including gangliosides (62). Serum samples were serially diluted commencing at 1:100. The antibody titer is the highest serum dilution that was defined by a basic optical density (OD) at $490 \mathrm{~nm}$. Serum is considered positive when the titer was 1:500 or more (63). Specific binding is detected using the reactants, which will generate a colored reaction product. Antibodies from a particular species react with the antigen, which binds to the solid phase and the bound antibodies are detected by the addition of horseradish peroxidase (HRP)-labeled antibody. ELISA combines the specificity of antibodies with the sensitivity of enzyme reactions. In one study, the specificity and sensitivity of an ELISA were reported to be $97 \%$ and $32 \%$ respectively (64). The main problem of ELISA method for detecting anti-ganglioside antibodies is the high unspecific binding of unknown antibodies of samples (called background) in all ELISA plate wells. The background of high unspecific binding affects the judgment of the results, making the ELISA prone to false positives. It is laborious to find the maximum dilution by gradient dilution.

\section{Immunodot assays}

Immunodot assay is a rapid and efficient assay for detecting antibodies against gangliosides (65). PVDF membranes are cut into appropriate sizes (squares, strips or other shape), and coated with purified gangliosides. Individual gangliosides are dissolved with organic solvents. The qualitative assay of anti-ganglioside antibody was optimized based on positive/negative sample testing results. Sera samples are typically diluted $1 / 50-1 / 200$. The secondary antibody, alkaline phosphatase (AP)-conjugated anti-human $\operatorname{IgG}$ and $\operatorname{IgM}$ is incubated for recognizing human serum antibodies, then subjected to a color reaction by an enzyme-reactive substrate to form a spotlike coloration observable by the naked eye. If the coated region has a brown speckled color, that means there are antibodies specific to given gangliosides antigen in the samples (Figure 1). Positive results: the antigen-coated area presents a clearly distinguishable circle or approximately circular shape, colored light blue-gray or dark blue-black, with a darker color than the blank control. Negative result: the color of the antigen-coated area is shallower or equivalent to the blank control area, or that of the antigencoated area is slightly darker than the blank control, but there is no clear boundary. Immunodot assays can detect multiple antibodies simultaneously. However, the inspection of testing results is somewhat subjective. For example, for a weak positive or suspected positive result, different people may give different judgment results. Therefore, the interpretation of the results generally requires 2-3 experienced personnel to make judgments. When there are differences in the results, other detection methods are needed to determine the results. It is reported that the sensitivity of immunoblotting method was $56 \%$ and specificity was $100 \%(64)$.

\section{Other detection methods}

Serum from some GBS patients is bound to single gangliosides or to a mixture of ganglioside complexes (GSCs), including anti-GD1a:GD1b antibodies, antiLM1-complex antibodies, anti-GM1:GalNAc-GD1a 


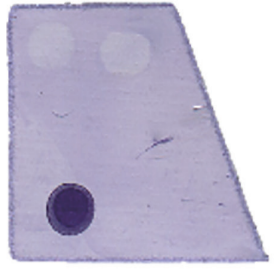

Strong positive

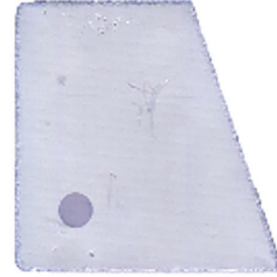

Positive

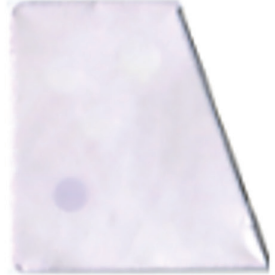

Weak positive

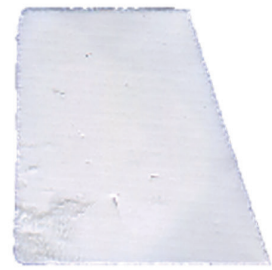

Negative

Figure 1 The test results of anti-ganglioside antibodies explained. Here, the C1Q antibody is used as an example of strong positive, positive, weak positive and negative.

antibodies, anti-GQ1b-complex antibodies, and other anti-glycolipid-complex antibodies (66). Furthermore, a small portion of sera binds only to the GSCs but not the individual gangliosides. Traditional antibody detection assays react with single ganglioside species that do not seem to greatly increase the diagnostic sensitivity of antibody testing. In 2012, the combinatorial glycol array method, a novel technique, was developed to test combinations of gangliosides and other glycolipids that significantly increase the sensitivity of serological testing (67). In this method, ganglioside solutions are diluted with methanol and GSCs are made by mixing equal volumes of different glycolipids. Antigens are then spotted onto PVDF membranes and each spot is separated from other spots by $2 \mathrm{~mm}$. The PDVF membranes are then blocked with $2 \%$ bovine serum albumin (BSA) for $1 \mathrm{~h}$ at room temperature. Serum is diluted (1:100) with $1 \%$ BSA incubated on PVDF membranes for $2 \mathrm{~h}$ at $4{ }^{\circ} \mathrm{C}$. And then washed three times with phosphate-buffered saline (PBS), the corresponding secondary antibody is diluted $(1: 1,000)$ and applied for $1 \mathrm{~h}$, washed with PBS, and PVDF membranes are washed with distilled water for $5 \mathrm{~min}$. The PVDF membranes are dried at room temperature in the dark. Reactivities to GSCs are expressed in fluorescence intensities detected using Image Quent TL software. Intensities greater than the mean plus 3 standard deviations for healthy controls are considered positive. In addition to a single ganglioside species, the glycosyl array method also tests antibodies against several glycolipid complexes that can identify antibodies in $53 \%$ of GBS patients, while only $13 \%$ were identified by ELISA (68). The detection of anti-GSC antibodies may prove useful in identifying clinical and pathological subtypes. The LM1:GA1-complex antibodies associated with AMAN, absence of sensory impairment and reversible conduction failure, anti-GalNAc-GD1a, antiGM1:GalNAc-GD1a, anti-GM1b:GA1, and anti-LM1:GA1 were associated with pure motor GBS (68).

\section{Comparison among different detection methods and kits}

Several commercial immunological assay kits are available worldwide for detecting anti-ganglioside antibodies such as immunodot assays (Euroimmun), line-immuno assay (GA Generic Assays), and ELISA (Buhlman). In one study, according to the clinical criteria of children with GBS, the specificity and sensitivity of immunoblotting were better than ELISA: the sensitivities of ELISA and immunoblotting methods were $32 \%$ and $56 \%$, and the specificities were $97 \%$ and $100 \%$, respectively (64). But the sensitivity and specificity are different for anti-ganglioside antibody detection in different commercial products (65). In developing detection methods for anti-ganglioside antibodies, different techniques are not necessarily expected to be fully concordant with each other, or superior to each other, as there is no recognized optimal assay for detecting these antibodies (69).

\section{Development of anti-ganglioside antibodies detection in China}

In China, the commercial kits, or in-house assays established in different clinical centers for antibody testing are usually ELISA and immunodot assays as elsewhere. Recently, immunodot assays have been further developed domestically. Several parameters may be adjusted from the current methods, such as ganglioside preparation, buffer composition, sample preparation, and time and temperature of incubation that may affect the detection sensitivity and specificity. The existence of 'gray areas' in immunology assays make the situation complicated. Identifying the color change in ELISA using an auto-measurement instrument should be less subjective than in immunodot with by eye observation. However, some reports had different conclusions $(64,70)$. Since key parameters of the commercial kits are usually manufacturers' proprietary information, 
comparisons of sensitivity and specificity of the products is not adequate for evaluating the pros and cons of different technologies.

Our lab has compared different types of kits from different manufacturers, and set up an in-house immunodot assay to extensively study the parameters affecting the detection results (unpublished data). There are rational positive correlations between some parameters (for example, purity of antigen, affinity and specificity of secondary antibody, activity of enzyme) and the accuracy of testing. Changing the concentration of surfactant in diluent buffer or washing buffer, the washing duration, the dose of antigen, and the dilution ratio of samples will change the specificity and sensitivity to the opposite orientations. For example, reducing the concentration of the surfactant (such as from $0.5 \%$ to $0.2 \%$ in a certain testing system) will increase the titer value of positive sample dramatically, and the positive rate from $2 \%$ to $15 \%$, even in a healthy patient group. It is reasonable to set up the assay using the following steps: first, set up the immunology assay with the reagents of the first class quantification, and with strict conditions: higher concentration of surfactant, longer washing duration, lower dose of antigen, etc., to ensure detection of the lowest positive rate (near zero) for the healthy group, and the positive signal from strong positive samples; second, relax the strict conditions to increase the detection titer value of the strong positive samples, while keeping the lowest positive rate from the healthy group, until the clinical requirements are met with clinical, randomized samples at a large scale.

A commercial kit from China was recently developed following the steps described above, with modified antigen solvents and dot technology to limit the antigen to quite a small region without diffusion, to keep the local antigen density. Using that kit, color spots with sharp margins will be obvious even when the weakest positive sample is tested, while the detection rate from the healthy group stays lower than $2 \%$ (anti-GM1) or goes to 0 (anti-GD1b and GQ1b). About 1,500 samples from suspected GBS patients in China were tested with this kit during the last several years, about 4/5 of IgG anti-GD1b positive patients were also IgG antiGM1 positive; a few anti-GD1b positive patients were also anti-GQ1b positive (unpublished data). Those findings are somewhat different from previous reports: anti-GQ1b cross-reacts with GD1b and GT1a and vice versa (20). For the case of double-positivity, the reports mainly involved a large number of patients with GQ1b and GT1a double-positive, and it may be due to the cross-reaction between the antibodies and these structurally similar antigens (51). However, in our study, serum neutralization analysis was performed on GD1b and GM1 double positive serum. For example, serum samples were mixed with GM1 solution $(50 \mu \mathrm{M})$ and incubated for 1 hour before detection of autoantibodies. Serum neutralization by the antigen GM1 did not affect the color development of antiGD1b autoantibody and vice versa. These results show that the anti-GD1b and anti-GM1 double-positive sera are not caused by insufficient specificity of antibodies (the antibodies cross-react with GD1b and GM1), and it is more likely that both antibodies of anti-GD1b and anti-GM1 exist in the patient's sera.

\section{Conclusions}

Anti-ganglioside antibodies can be detected using several methods, including ELISA and immunodot assays. All methods have advantages and limitations. The evaluation for anti-ganglioside antibodies mainly includes two aspects. First, these methods differ substantially in their accuracy, including sensitivity and specificity. The accuracy values obtained are biased for different subgroups and are presumably higher than in actual practice in some reports. The specificity and sensitivity should be related to the disease spectrum. Second, several parameters (washing buffer, washing duration, the dose of antigen) are different in different detection methods. The immunodot assay has undergone many changes, making it more efficient and more convenient. Specific anti-ganglioside antibody detection can be used to define subgroups of GBS patients. Absolute sensitivities and specificities are unavailable. There is still a need for extensive standardization of all commercial anti-ganglioside assays.

\section{Acknowledgments}

Funding: YY was supported by the National Natural Science Foundation of China (No. 81571596) and the Fundamental Research Funds for the Central Universities (No. GK201701009).

\section{Footnote}

Provenance and Peer Review: This article was commissioned by the Guest Editors (Hai-Feng Li and Xiangjun Chen) for the series "Laboratory Investigations in Neuroimmunological Diseases and Their Clinical 
Significance" published in Annals of Translational Medicine. The article has undergone external peer review.

Conflicts of Interest: All authors have completed the ICMJE uniform disclosure form (available at https://atm.amegroups. com/article/view/10.21037/atm-20-2285/coif). The series "Laboratory Investigations in Neuroimmunological Diseases and Their Clinical Significance" was commissioned by the editorial office without any funding or sponsorship. All authors report grants from the National Natural Science Foundation of China (No. 81571596), and grants from the Fundamental Research Funds for the Central Universities (No. GK201701009), during the conduct of the study. The authors have no other conflicts of interest to declare.

Ethical Statement: The authors are accountable for all aspects of the work in ensuring that questions related to the accuracy or integrity of any part of the work are appropriately investigated and resolved.

Open Access Statement: This is an Open Access article distributed in accordance with the Creative Commons Attribution-NonCommercial-NoDerivs 4.0 International License (CC BY-NC-ND 4.0), which permits the noncommercial replication and distribution of the article with the strict proviso that no changes or edits are made and the original work is properly cited (including links to both the formal publication through the relevant DOI and the license). See: https://creativecommons.org/licenses/by-nc-nd/4.0/.

\section{References}

1. Hakomori S. Glycosylation defining cancer malignancy: New wine in an old bottle. Proc Natl Acad Sci U S A 2002;99:10231-3.

2. Yu RK, Bieberich E, Xia T, et al. Regulation of ganglioside biosynthesis in the nervous system. J Lipid Res 2004;45:783-93.

3. Ferreira IG, Pucci M, Venturi G, et al. Glycosylation as a Main Regulator of Growth and Death Factor Receptors Signaling. Int J Mol Sci 2018;19:580.

4. Kaida K, Ariga T, Yu RK. Antiganglioside antibodies and their pathophysiological effects on Guillain-Barre syndrome and related disorders--A review. Glycobiology 2009;19:676-92.

5. Wanleenuwat P, Iwanowski P, Kozubski W. Antiganglioside antibodies in neurological diseases. J Neurol Sci 2020;408:116576.
6. Sántha P, Dobos I, Kis G, et al. Role of Gangliosides in Peripheral Pain Mechanisms. Int J Mol Sci 2020;21:1005.

7. Hafer-Macko C, Hsieh ST, Ho TW, et al. Acute motor axonal neuropathy: An antibody-mediated attack on axolemma. Ann Neurol 1996;40:635-44.

8. Svennerholm L. Designation and Schematic Structure of Gangliosides and Allied Glycosphingolipids. Prog Brain Res 1994;101:XI-XIV.

9. Emilien D, Hugh W. Diagnostic Utility of Auto Antibodies in Inflammatory Nerve Disorders. J Neuromuscul Dis 2015;2:107-12.

10. Anandan C, Khuder SA, Koffman BM. Prevalence of autonomic dysfunction in hospitalized patients with Guillain-Barré syndrome: Short Reports. Muscle Nerve 2017;56:331-3.

11. Van der Meché FG, van Doorn PA, Meulstee J, et al. Diagnostic and Classification Criteria for the GuillainBarré Syndrome. Eur Neurol 2001;45:133-9.

12. Sejvar JJ, Kohl KS, Gidudu J, et al. Guillain-Barré syndrome and Fisher syndrome: Case definitions and guidelines for collection, analysis, and presentation of immunization safety data. Vaccine 2011;29:599-612.

13. Av S, Pa van D. Intravenous immunoglobulin for GuillainBarre syndrome. 2012;64.

14. Rees JH, Gregson NA, Hughes RAC. Anti-ganglioside GM 1 antibodies in guillain-barré syndrome and their relationship to Campylobacter jejuni infection: Anti-GM 1 Antibodies in GBS. Ann Neurol 1995;38:809-16.

15. Ohtsuka K, Nakamura Y, Tagawa Y, et al. Immunoadsorption therapy for Fisher syndrome associated with IgG anti-GQ1b antibody. Am J Ophthalmol 1998;125:403-6.

16. Ishii J, Yuki N, Kawamoto M, et al. Recurrent GuillainBarré syndrome, Miller Fisher syndrome and Bickerstaff brainstem encephalitis. J Neurol Sci 2016;364:59-64.

17. Dimachkie MM, Barohn RJ. Guillain-Barré Syndrome and Variants. Neurol Clin 2013;31:491-510.

18. Kuwabara S, Nakata M, Sung JY, et al. Hyperreflexia in axonal Guillain-Barré syndrome subsequent to Campylobacter jejuni enteritis. J Neurol Sci 2002;199:89-92.

19. Meena AK, Archana AD, Reddy GC, et al. Antiganglioside Antibodies in Sub Types of Guillain-Barre Syndrome in an Indian Population. J Med Sci 2010;10:138-42.

20. Nagashima T, Koga M, Odaka M, et al. Continuous spectrum of pharyngeal-cervical-brachial variant of Guillain-Barré syndrome. Arch Neurol 2007;64:1519-23.

21. Shang $P$, Zhu $M$, Wang $Y$, et al. Axonal variants of Guillain-Barré syndrome: an update. J Neurol 
2021;268:2402-19.

22. Kim JK, Bae JS, Kim D-S, et al. Prevalence of AntiGanglioside Antibodies and Their Clinical Correlates with Guillain-Barré Syndrome in Korea: A Nationwide Multicenter Study. J Clin Neurol 2014;10:94.

23. Arányi Z, Kovács T, Sipos I, et al. Miller Fisher syndrome: brief overview and update with a focus on electrophysiological findings: Miller Fisher syndrome. Eur J Neurol 2012;19:15-20, e1-3.

24. Sawaya R. Anti-GQ1b Spectrum Disorders. J Clin Neuromuscul Dis 2019;21:52-3.

25. Kaida K. Autoantibodies in Guillain-Barré Syndrome (GBS). In: Kusunoki S. Neuroimmunological Diseases. Springer, 2016:165-85.

26. O'Hanlon GM, Paterson GJ, Veitch J, et al. Mapping immunoreactive epitopes in the human peripheral nervous system using human monoclonal anti-GM1 ganglioside antibodies. Acta Neuropathologica 1998;95:605-616.

27. Ho TW, Willison HJ, Nachamkin I, et al. Anti-GD1a antibody is associated with axonal but not demyelinating forms of Guillain-Barré syndrome. Ann Neurol 1999;45:168-73.

28. Koga M, Yoshino H, Morimatsu M, et al. Anti-GT1a IgG in Guillain-Barré syndrome. J Neurol Neurosurg Psychiatry 2002;72:767-71.

29. Kaida K, Kusunoki S, Kamakura K, et al. GalNAc-GD1a in human peripheral nerve: target sites of anti-ganglioside antibody. Neurology 2003;61:465-70.

30. Rodríguez Y, Rojas M, Pacheco Y, et al. Guillain-Barré syndrome, transverse myelitis and infectious diseases. Cell Mol Immunol 2018;15:547-62.

31. Schnaar RL. Gangliosides in Axon Stability and Regeneration. Glycoscience Biol Med 2015;535-42.

32. Kokubun N, Nishibayashi M, Uncini A, et al. Conduction block in acute motor axonal neuropathy. Brain 2010;133:2897-908.

33. Hughes RA, Cornblath DR, Willison HJ. Guillain-Barré syndrome in the 100 years since its description by Guillain, Barré and Strohl. Brain 2016;139:3041-7.

34. Yuki N, Kokubun N, Kuwabara S, et al. Guillain-Barré syndrome associated with normal or exaggerated tendon reflexes. Journal of Neurology 2012;259:1181-90.

35. Figueras A, Morales-Olivas FJ, Capella D, et al. Bovine gangliosides and acute motor polyneuropathy. BMJ 1992;305:1330-1331.

36. Wu X, Wu W, Wang Z, et al. More Severe Manifestations and Poorer Short-Term Prognosis of GangliosideAssociated Guillain-Barré Syndrome in Northeast China.
PLoS One 2014;9:e104074.

37. Odaka M, Yuki N, Nobile-Orazio E, et al. Antibodies to GM1(NeuGc) in Guillain-Barre's syndrome after ganglioside therapy. J Neurol Sci 2000;175:96.

38. Roggenbuck D, Delmont E, Reinhold D, et al. Autoimmune Peripheral Neuropathies and Contribution of Antiganglioside/Sulphatide Autoantibody Testing. Mediterr J Rheumatol 2020;31:10.

39. Visser LH, Van Der Meché FGA, Van Doorn PA, et al. Guillain-Barré syndrome without sensory loss (acute motor neuropathy): A subgroup with specific clinical, electrodiagnostic and laboratory features. Brain 1995;118:841-7.

40. McKhann GM, Cornblath DR, Griffin JW, et al. Acute motor axonal neuropathy: A frequent cause of acute flaccid paralysis in China. Ann Neurol 1993;33:333-42.

41. Kusunoki S, Chiba A, Kon K, et al. N-acetylgalactosaminyl GD1a is a target molecule for serum antibody in GuillainBarré syndrome. Ann Neurol 1994;35:570-6.

42. Vernino S, Wolfe GI. Antibody Testing in Peripheral Neuropathies. Neurol Clin 2007;25:29-46.

43. Yuki N, Tagawa Y. Acute cytomegalovirus infection and IgM anti-GM2 antibody. J Neurol Sci 1998;154:14-7.

44. Kusunoki S, Iwamori M, Chiba A, et al. GM1b is a new member of antigen for serum antibody in Guillain-Barré syndrome. Neurology 1996;47:237.

45. Gregson NA, Jones D, Thomas PK, et al. Acute motor neuropathy with antibodies to GM1 ganglioside. J Neurol 1991;238:447-51.

46. Yoshino H, Utsunomiya I, Taguchi K, et al. GalNAcGD1a is localized specifically in ventral spinal roots, but not in dorsal spinal roots. Brain Res 2005;1057:177-80.

47. Yuki N, Wim Ang C, Koga M, et al. Clinical features and response to treatment in Guillain-Barré syndrome associated with antibodies to GM1b ganglioside. Ann Neurol 2000;47:314-21.

48. Usuki S, Sanchez J, Ariga T, et al. AIDP and CIDP having specific antibodies to the carbohydrate epitope (NeuAc $\alpha 2-8$ NeuAc $\alpha 2-3$ Gal $\beta 1-4 G l c-)$ of gangliosides. J Neurol Sci 2005;232:37-44.

49. Kusunoki S, Chiba A, Kanazawa I. Anti-GQ1b IgG antibody is associated with ataxia as well as ophthalmoplegia. Muscle Nerve 1999;22:1071-4.

50. Yuki N. Tryptophan-immobilized column adsorbs immunoglobulin G anti-GQ1b antibody from Fisher's syndrome: A new approach to treatment. Neurology 1996;46:1644-51.

51. Susuki K, Yuki N, Hirata K. Fine specificity of anti-GQ1b 
IgG and clinical features. J Neurol Sci 2001;185:5-9.

52. The GBS Classification Group, Wakerley BR, Uncini A, et al. Guillain-Barré and Miller Fisher syndromes-new diagnostic classification. Nat Rev Neurol 2014;10:537-44.

53. Shahrizaila N, Yuki N. Bickerstaff brainstem encephalitis and Fisher syndrome: anti-GQ1b antibody syndrome. J Neurol Neurosurg Psychiatry 2013;84:576-83.

54. Ito M, Kuwabara S, Odaka M, et al. Bickerstaff's brainstem encephalitis and Fisher syndrome form a continuous spectrum: Clinical analysis of 581 cases. J Neurol 2008;255:674-82.

55. Wakerley BR, Derek S, Yee-Cheun C, et al. Atypical Bickerstaff brainstem encephalitis: ataxic hypersomnolence without ophthalmoplegia. J Neurol Neurosurg Psychiatry 2013;84:1206-7.

56. Alaedini A, Latov N. Detection of Anti-Gm1 Ganglioside Antibodies in Patients with Neuropathy by a Novel Latex Agglutination Assay. J Immunoassay 2000;21:377-86.

57. Escande-Beillard N, David MJ, Portoukalian J, et al. A sensitive flow cytometry method for anti-GM1 antibodies detection. J Neuroimmunol 2002;125:163-9.

58. Fabis-Pedrini MJ, Bundell C, Wee CK, et al. Prevalence of anti-aquaporin 4 antibody in a diagnostic cohort of patients being investigated for possible neuromyelitis optica spectrum disorder in Western Australia. J Neuroimmunol 2018;324:76-80.

59. Dalmau J, Tüzün E, Wu HY, et al. Paraneoplastic anti-Nmethyl-D-aspartate receptor encephalitis associated with ovarian teratoma. Ann Neurol 2007;61:25-36.

60. Willison HJ, O'Leary CP, Veitch J, et al. The clinical and laboratory features of chronic sensory ataxic neuropathy with anti-disialosyl IgM antibodies. Brain 2001;124:1968-77.

61. Ilyas AA, Quarles RH, Dalakas MC, et al. Monoclonal IgM in a patient with paraproteinemic polyneuropathy binds to gangliosides containing disialosyl groups. Ann

Cite this article as: Zhu W, Li K, Cui T, Yan Y. Detection of anti-ganglioside antibodies in Guillain-Barré syndrome. Ann Transl Med 2023;11(7):289. doi: 10.21037/atm-20-2285
Neurol 1985;18:655-9.

62. Lyu RK, Tang LM, Cheng SY, et al. Guillain-Barré syndrome in Taiwan: a clinical study of 167 patients. J Neurol Neurosurg Psychiatry 1997;63:494-500.

63. Yuki N, Taki T, Handa S. Antibody to Ga1NAc-GD1a and Ga1NAc-GM1b in Guillain-Barré syndrome subsequent to Campylobacter jejuni enteritis. J Neuroimmunol 1996;71:155-61.

64. Bonyadi MR, Barzegar M, Badalzadeh R, et al. Comparison of Immunoblotting and ELISA for Detection of Anti-Ganglioside Antibodies in Children with GuillainBarre Syndrome. Iran J Immunol 2010;7:117-23.

65. Chabraoui F, Derrington EA, Mallie-Didier F, et al. Dotblot immunodetection of antibodies against GM1 and other gangliosides on PVDF-P membranes. J Immunol Methods 1993;165:225-230.

66. Kaida K, Morita D, Kanzaki M, et al. Ganglioside complexes as new target antigens in Guillain-Barré syndrome: Antibody to Ganglioside Complex. Ann Neurol 2004;56:567-571.

67. Chevolot Y (ed). Carbohydrate microarrays: methods and protocols. New York: Humana Press, 2012.

68. Goodfellow JA, Willison HJ. Antiganglioside, antiganglioside-complex, and antiglycolipid-complex antibodies in immune-mediated neuropathies. Curr Opin Neurol 2016;29:572.

69. Franciotta D, Gastaldi M, Biagioli T, et al. Antiganglioside antibodies: experience from the Italian Association of Neuroimmunology external quality assessment scheme. Clin Chem Lab Med 2018;56:1921-5.

70. Caudie C, Pinon A, Bouhour F, et al. Comparison of Commercial Tests for Detecting Multiple Anti-Ganglioside Autoantibodies in Patients with Well-Characterized Immune-Mediated Peripheral Neuropathies. Clin Lab 2013;59:1277-87. 